\section{Endoscopic resection of a giant gastric polyp}

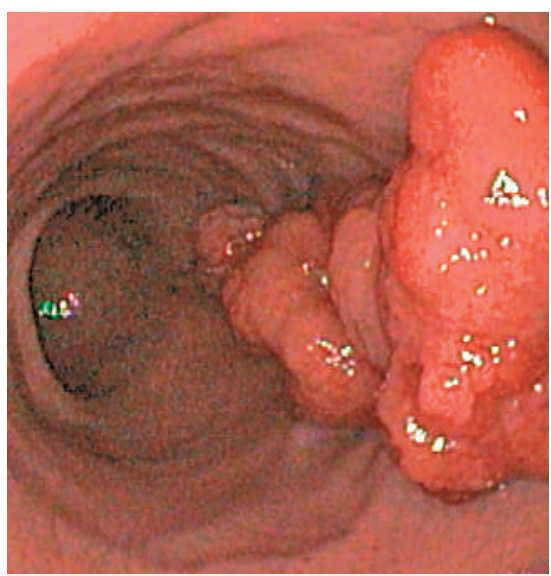

Fig. 1 Gastric polyp inserting in the corpus, large free part about $10 \mathrm{~cm}$ in length. Ulcerated area covered with fibrin, about $1.5 \mathrm{~cm}$ in diameter.

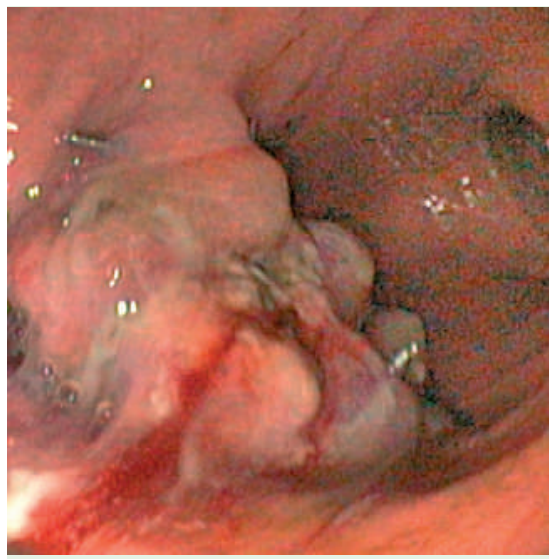

Fig. 3 Polyp base subsequent to resection and injection of epinephrine solution to control minor bleeding.

A 45-year-old woman was admitted to our department having suffered from intermittent abdominal pain in the preceding months. Endoscopy of the upper gastrointestinal tract revealed a bizarrely shaped polyp, $10 \mathrm{~cm}$ in size and with a broad base located in the gastric body (৫ Fig. 1), which at times protruded through the pylorus ( $\bullet$ Fig. 2). Such a giant gastric polyp is a rare finding [14]. The surface of the polyp, positioned within the pyloric channel, was ulcerated. The polyp was easily retracted into the gastric cavity. Endosonographic examination revealed no major feeding vessels within the polyp. No infiltration into dee-

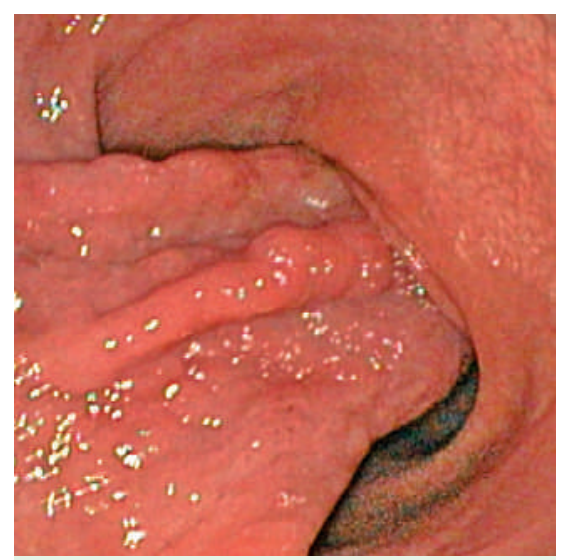

Fig. 2 Polyp protruding through the pylorus. This probably caused the patient's pain by gastric outlet obstruction and anemia due to ulceration of mechanically stressed surfaces.

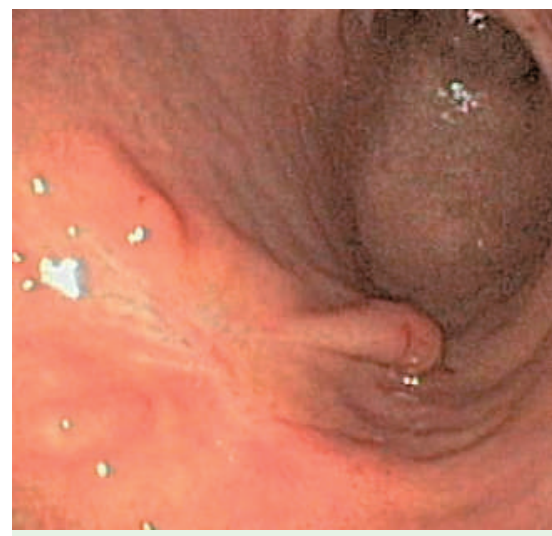

Fig. 4 Follow-up examination 18 months after endoscopic resection. White scar corresponds to former polyp base.

per layers of the gastric wall was observed. Histological study of biopsies taken gave no evidence of malignancy.

The option of surgical resection was discussed with the patient, but she preferred an endoscopic approach. An overtube was placed in the upper esophagus to protect against aspiration. To reduce bleeding, a total of $30 \mathrm{ml}$ epinephrine solution (diluted $1: 10000$ ) was injected into the base of the polyp. A snare was positioned close to the base and electrical current applied for a total of $45 \mathrm{~min}$, but the polyp was not completely transected. The endoscope was therefore removed (leaving the snare in place) and a second snare was placed to resect the upper $5 \mathrm{~cm}$ of the polyp
(ه Fig. 3). The first snare was then repositioned, the remaining part of the polyp was removed in a three-step-procedure and its fragments were collected with a Dormia basket. Discreet bleeding from the center of the polyp base was well controlled by epinephrine injection. Control examination revealed a small remnant which was removed 3 months later as histology documented a hyperplastic polyp with an increased proliferation rate. The last follow-up examination, 18 months after resection, showed an excellent result as only a white scar was evident at the point of resection ( $\bullet$ Fig. 4 ).

Endoscopy_UCTN_Code_CCL_1AB_2AD_3AB

\section{R. Niehues, W. Domschke, T. Pohle}

Department of Medicine B, University of Münster, Münster, Germany

\section{References}

1 Chen HW, Lu CH, Shun CT, Lin MT, Tsang YM. Gastric outlet obstruction due to giant hyperplastic gastric polyps. J Formos Med Assoc 2005 ; 104: $852-855$

2 Brandimarte G, Tursi A, Elisei W et al. Symptomatic gastric leiomyoma mimicking giant gastric polyp: endoscopic diagnosis and removal. Eur Rev Med Pharmacol Sci 2004; 8: 107-110

3 Sebastian S, Addley J, Crotty P, Buckey M. Giant gastric polyp. Gastrointest Endosc 2004; 59: $398-399$

4 Dell'Abate P, Del Rio P, Soliani P, Sianesi M. Endoscopic polypectomy with the use of endoloop in giant gastric polyp: a case report. Acta Biomed Ateneo Parmense 2001; 72: $105-108$

\section{Bibliography}

DOI 10.1055/s-2007-966882

Endoscopy 2008; 40: E50

(c) Georg Thieme Verlag KG Stuttgart · New York . ISSN 0013-726X

\section{Corresponding author}

\section{R. Niehues, MD}

Department of Medicine B

University of Münster

Albert-Schweitzer-Str. 33

48129 Münster

Germany

Fax: +49-251-8347570

ralf.niehues@gmx.de 